\title{
Applying the Theory of Planned Behavior (TPB) in Investigating Consumption Behavior in Vietnam
}

\author{
Ha Thu Luong ${ }^{1}$ Duc Canh Le ${ }^{2}$ Trang Nhat Tran² Chi Ngoc Bao Nguyen ${ }^{2}$ \\ Son Khanh $\operatorname{Tran}^{3}$ Huyen Khanh Ngo 4
}

1. School of Advanced Education Programs, National Economics University, Hanoi, Vietnam

2. Department of Advanced Accounting, National Economics University, Hanoi, Vietnam

3. Department of Business Administration, National Economics University, Hanoi, Vietnam

4. Department of Human Resource Management, National Economics University, Hanoi, Vietnam

* E-mail of the corresponding author: haluongthu@,neu.edu.vn

\begin{abstract}
This study explored the consumer behavior based on TPB model in Vietnam. The hypotheses are empirically tested using survey data obtained from consumer who purchased green products of household appliances in Hanoi- the capital of Vietnam. During the study, the research team added the "trend" variable which is a characteristic variable in Vietnam. The results of the multiple regression analysis show that attitude, subjective norm, perceived behavioral control, trend have significant and positive effect on household appliances product. The research findings are discussed and implications for government, manufacturing businesses, retail businesses to embrace green consumption behavior
\end{abstract}

Keywords: Consumption Behavior; Vietnam; TPB; Household appliances

DOI: $10.7176 / \mathrm{EJBM} / 12-18-16$

Publication date:June 30th 2020

\section{Introduction}

The economy in recent years has been developing rapidly, along with emerging environmental issues such as climate change, urban sprawl, ozone layer depletion, Economic growth with environmental protection and improvement has a binding, complementary relationship. With a positively growing economy, Vietnam also indicates that one of the most important actions at the moment is protecting the environment as well as spreading out the information about direct consequence of environmental problems. When consumers are aware of environmental protection issues, they tend to express more concern about the consumption and use of green environmentally friendly products.

In Vietnam, people's awareness of green consumption behaviors is still limited. Consumers are partly willing to pay more for green products but they are not fully aware of the concepts of green products, and how they need to be used to help these products be purchased, used and disposed of waste properly.

To make green consumption be more effective, it must start from the popular products that are used and consumed by the highest consumers in every household in Vietnam. In particular, household appliances are devices operated by electrical energy that are used in home to serve people's daily life, such as: washing machines, air conditioners, vacuum cleaners, fans, induction cookers, electric rice cookers, etc. The monthly electricity bill will reduce if we can manage the home electrical energy system deployed and the use of energy-saving products at home is encouraged.

Therefore, research related to household appliances green consumption in Vietnam is very essential to promote and maintain the intention and behavior of green consumption of each customer as well as building a long- term and sustainable strategy for developing economy at the same time with protecting the environment. 


\section{Theoretical Framework}

\subsection{Theory of Planned Behavior}

TPB is one of the simple and competent frameworks which is used for examining the individual's intent to perform context-specific actions (Russo, 2015). The TPB framework is an expansion of the Theory of reasoned action (TRA)- Ajzen's previous research with Fishbein in 1975 and 1980. According to the TRA model, intention is a central factor, which is influenced by two factors "Attitude" and "Subjective Norm" in order to perform a given behavior. The stronger the intention to perform behavior, the more likely the behavior will be performed. Developing TRA model to TPB model, Ajzen (1991) still supports this point of view and the role of two factors "Attitude" and "Subjective Norms" and added "Perceived Behavioral Control". Ajzen (1991) also affirmed that "Perceived Behavioral Control" along with "Behavioral Intention" can be used directly in predicting behavior while Attitude and Subjective Norm have indirect influence on behavior through intention.

TPB has been used as the model in other researchers include the green product purchase behavior (Maichum, 2016), organic food purchase behavior (Urban J, 2012), online buying behavior (Al-Azzam, 2014). Information system researchers (Nchise, 2012) and genetically modified food researchers (Kim, 2014) also used TPB in their studies.

\subsection{Consumption Behavior}

The idea of consumption defined by Webb (1993) in the following word: "Consumption is the evaluating, buying, using and disposing of products and services." The study of consumer behaviour is concerned with all aspects of purchasing behaviour - from pre-purchase activities through to post-purchase consumption, evaluation and disposal activities. It is also concerned with all persons involved, either directly or indirectly, in purchasing decisions and consumption activities including brand-influencers and opinion leaders. Research has shown that consumer behaviour is difficult to predict, even for experts in the field. However, new research methods such as ethnography and consumer neuroscience are shedding new light on how consumers make decisions.

\subsection{Literature Review}

The Theory of Planned Behavior suggested by Icek Ajzen (1991) is a prominent theory that has been used as an approach and the original model in studies about consumption intention and behavior by many researchers, especially green consumption intention and behavior. Although the products and further developments from the TPB model in many studies are different, many researchers have admitted the important role of the TPB model in finding the final results. Product knowledge, along with price was an additional variable included by Syed S.Alam et al (2019) in their proposed model applied from the TPB model. The research results of Syed S.Alam showed that: Attitude, subjective norms, awareness of behavior control, understanding and reasonable price have a significant influence on purchasing intent. Kamonthip Maichum et al. (2016) also affirmed the role of understanding, particularly environmental understanding in the process of assessing green consumer intent. However, Changhyun Nam et al (2017) denied the dominant effect of perceived behavioral control while adding "Expectation" and "Perception" to three available factors from the TPB model.

TPB has been used as the model in other researchers include the green product purchase behaviour (Maichum, 2016), organic food purchase behaviour (Urban J, 2012), online buying behaviour (Al-Azzam, 2014). Information system researchers (Nchise, 2012) and genetically modified food researchers (Kim, 2014) also used TPB in their studies.

\section{Research model, hypothesis and methodology}

\subsection{Research model}

Based on the theoretical framework and summary of previous research, we prepared our research model of factors affecting green consumption behavior in Vietnam (Figure1). Beside testing 3 factors from the available TPB model, we add one more variable "Trend" after examining Vietnam condition. 
Figure 1. Model of factors affecting Vietnamese' green consumption behavior

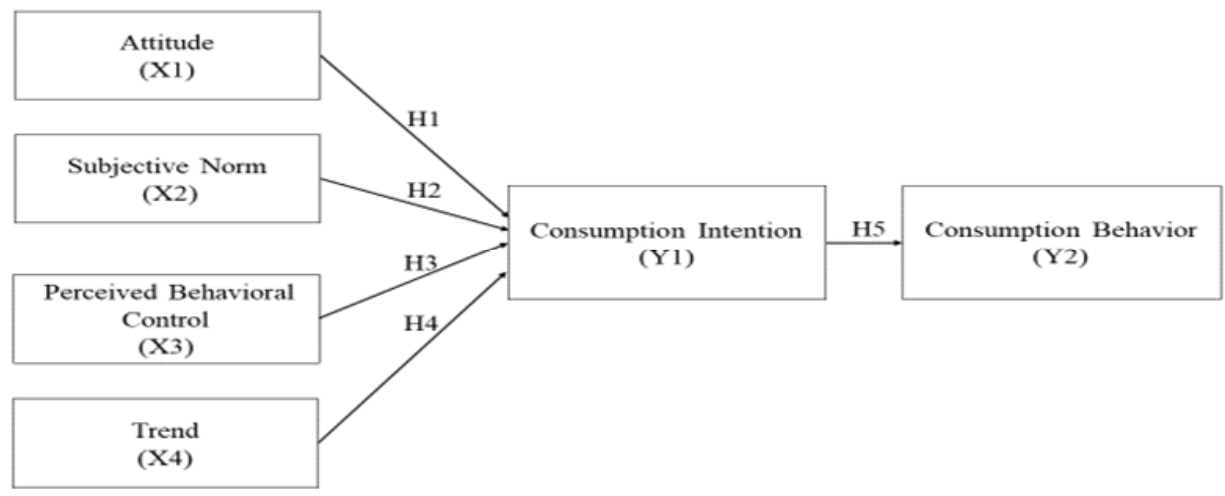

Along with defined factors, five hypotheses (stated below) were constructed to examine the impact of independent variables (attitude, subjective norm, perceived behavioral control and trend).

\subsubsection{Attitude}

Attitude is an independent factor that directly affect the actual behavior of consumers, expressed in the degree to which the performance of the behavior is evaluated positive or negative (Ajzen, 1991). Hoang Trong Hung et al (2018) concluded that "Attitude" is the strongest factor that directly influences consumption intention and thereby indirectly affects green consumption behavior. Syed S. Alam et al (2019) and Junghwa Son et al (2017) also confirmed the significant influence of attitude on consumption intention. Moreover, our progress of investigating deeply Vietnamese customers behavior through surveying shows that there is almost no gap between intention and behavior. Therefore, there is no difference between consumption intention and consumption behavior in Vietnam.

\section{H1: “Attitude” has positive impact on consumption intention.}

\subsubsection{Subjective norm}

Subjective norm is the social factors affecting consumption behavior in the TPB model (Ajzen, 1991). It was defined by Ajzen as the influence of society on the perception of people about to perform or not to perform the behavior. Shwu- Ing Wu and Jia- Yi Chen (2014), Syed S. Alam et al (2019) also successfully demonstrated a positive relationship between subjective norm and consumer intention. On the contrary, Junghwa Son et al (2007) denied the influence of subjective norm and excluded this variable from the research model.

\section{H2: "Subjective norm" has positive impact on consumption intention.}

\subsubsection{Perceived Behavioral Control}

According to the theory of planned behavior, perceived behavioral control refers to the individual perception about it is easy or difficult to perform a certain behavior, or the degree to which an individual controls the behavior performance (Ajzen, 1991). Ajzen also suggested that perceived behavioral control, besides directly affecting the intention to perform the behavior, can also be used to predict consumption behavior. Based on the theory of planned behavior, Syed S. Alam et al (2019), Junghwa Son et al (2017) emphasizes this point of view by indicating the direct influence of perceived behavioral control on the intention to consume green products. However, Changhyun Nam et al (2017) do not accept the hypothesis of positive effects on green consumption intention of perceived behavioral control.

\section{H3: “Perceived Behavioral Control” has positive impact on consumption intention.}

\subsubsection{Trend}

Through deep interview with some Vietnamese customers, we realize that many customers tend to buy a product when seeing many others evaluate positively that one. They think this way is more convenient and time- saving rather than finding and evaluating between several products before making the final decision. This is the basis for 
our research team to test the influence of additional variable named Trend. According to compilation of Language Institution on Vietnamese dictionary (Da Nang Publisher, 2001), trend refers to "the inclination towards a certain direction in the process of operation and the inclination to certain activities aimed at a essential goal for oneself over a long period of time". We also stated that green consumption trend is a combination of collectivism and social influence. Thus, the below hypothesis is illustrated:

\section{H4: "Trend" has positive impact on consumption intention.}

\subsubsection{Consumption intention and consumption behavior}

Furthermore, many researchers had considered relation between consumption intention and behavior. It is widely belief that consumption intention is intermediary factor affecting to consumption behavior. In details, one of the most striking features in "Theory of reasoned action" - Fishbein and Icek Ajzen (1967) and "Theory of planned behavior" - Ajzen $(1985,1991)$ lies on the major impact of intention to behavior. According to Ajzen, intention is the recapitulation of all emotional factors having effect on behavior, showing a person's desire to experience as well as persistence to perform behavior. Intention is assumed as intermediary premise of behavior that greater intention is established, the higher possibility in performing behavior. Thus, factors affecting consumption intention do have impact on consumption behavior. Therefore, the last hypothesis is developed as follows:

\section{H5: “Consumption intention” has positive impact on consumption behavior.}

\subsection{Research Methodology}

Meta-analysis: Our research team used Google as search tools, selectively analyzed 50 different results of academic magazines, research articles that are shown and closest to the key term "Factors + Green Consumption Behavior + Green Products" in both English and Vietnamese. Moreover, we also focus on latest articles about green consumption behavior in various fields.

Qualitative method: After having deep interview with several Vietnamese customers at electronic centers, we come up to the assumed research model with additional variable named Trend.

\section{Linear regression quantitative method - questionnaire survey:}

The questionnaire was constructed based on mentioned literature and developed hypotheses. There are two parts of the survey: the first part showed all demographic information to the sample and the second one presented question for evaluating the influence of four independent variables on dependent variable (green consumption behavior). Because of resource limitation, we only approach consumers who live in Hanoi city.

\subsection{Sample characteristics}

The official survey, conducted in Hanoi - capital city of Vietnam from October 2019 to February 2020, focus on application of TPB model in testing green consumption behavior in the field of household appliances. Although convenience sampling methodology is used, our research group try to ensure the representative of sample by various characteristics of consumers. The answers then were selected to eliminate invalid, missing important data as well as testing logicality. In a whole, 357 out of 461 completed and distinct questionnaires were used for this final analysis in following parts. In terms of allocation, 275 questionnaires $-77 \%$ were collected online and the other 82 questionnaires $-23 \%$ from offline approach. 


\subsection{Descriptive statistics}

ATTITUDE

$\begin{array}{lllllllllll}0 \% & 10 \% & 20 \% & 30 \% & 40 \% & 50 \% & 60 \% & 70 \% & 80 \% & 90 \% & 100 \%\end{array}$

I like to buy green household appliance

Buying green household appliance is a good idea

I am interested in buying green household appliance

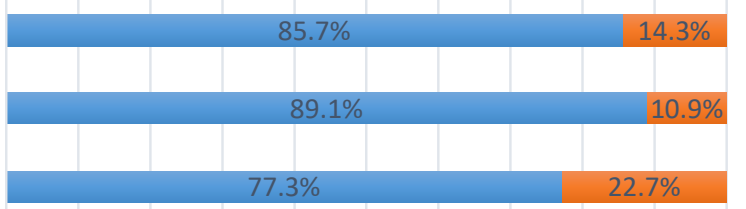

Agree Disagree

\section{SUBJECTIVE NORM}

$\begin{array}{llllllllllll}0 \% & 10 \% & 20 \% & 30 \% & 40 \% & 50 \% & 60 \% & 70 \% & 80 \% & 90 \% & 100 \%\end{array}$

My family advise me to buy green household appliance

My friends advise me to buy green household appliance

Important others people advise me to buy green household appliance

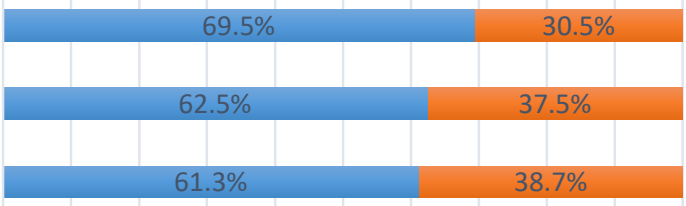

Agree Disagree

\section{PERCEIVED BEHAVIORAL CONTROL}

$\begin{array}{lllllllllll}0 \% & 10 \% & 20 \% & 30 \% & 40 \% & 50 \% & 60 \% & 70 \% & 80 \% & 90 \% & 100 \%\end{array}$

I will buy green household appliances even my friends tell me not to buy

Buying green household appliances is within my control

I can afford to buy green household appliance

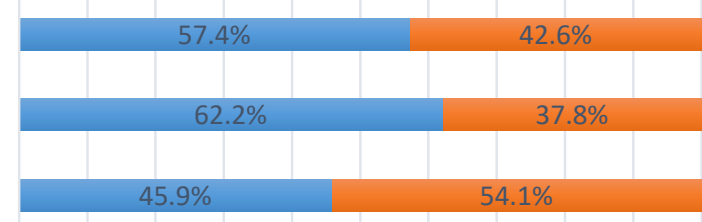

Agree Disagree

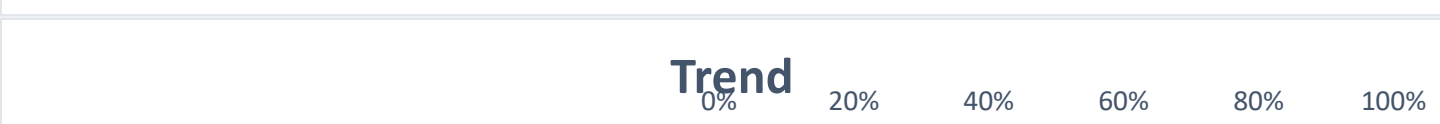

I know about green household appliances through my family

Most of my close friends and family use green household

I will buy if people surrounding me choose green household

I believe in the choice of the majority

Agree

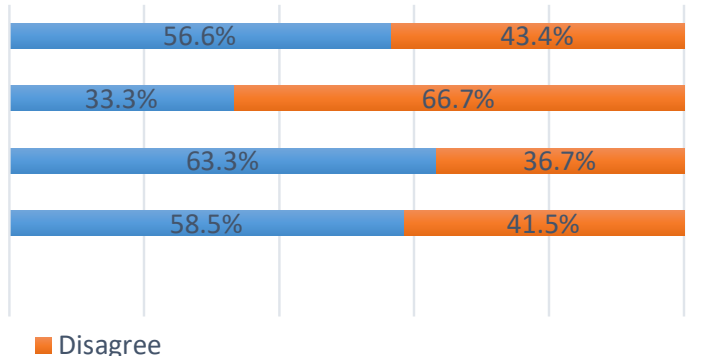




\section{CONSUMPTION INTENTION}

$\begin{array}{lllllllllll}0 \% & 10 \% & 20 \% & 30 \% & 40 \% & 50 \% & 60 \% & 70 \% & 80 \% & 90 \% & 100 \%\end{array}$

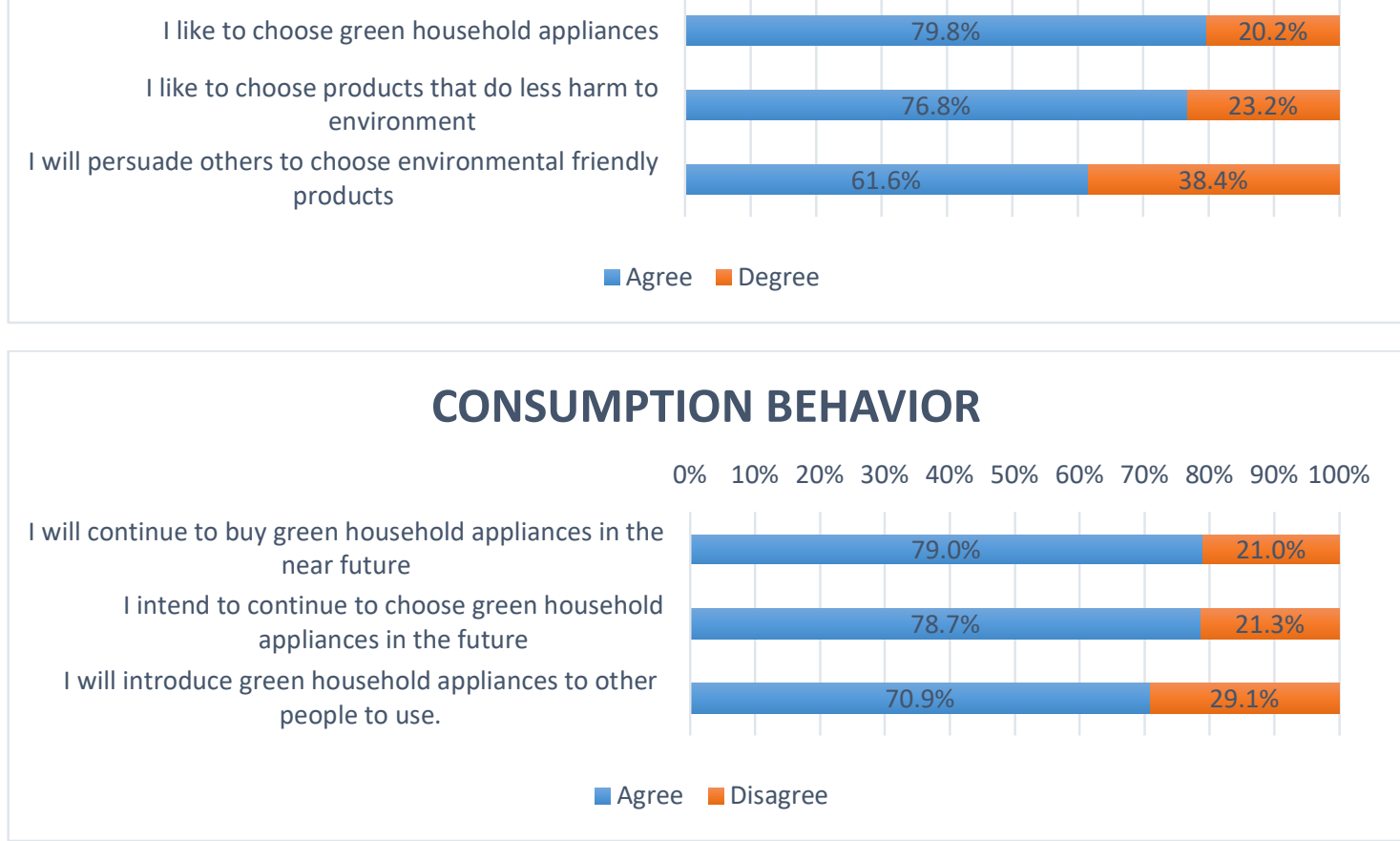

Table 1. Descriptive statistics result

According to descriptive statistics, most of consumers express positive attitude about green consumption behavior of green household appliances (GHA). Especially, $89.1 \%$ of consumers express positive thought of buying the products, $85.7 \%$ prefer to purchase and $77.3 \%$ shows favorable attitude toward green household appliances.

Subjective norm is the second most necessary determinants to intention in TPB model. This key term is referred to social influence, indicating belief of a person about whether or not should he engage in the behavior under peers and important people evaluation (Ajzen, 1991). Following the description, our research group take three sources of influence on consumers, they are from family members, close friends and other important people like colleagues or idols. Outstanding impact made by group of consumers' relatives, accounting for $69.5 \%$ acceptance of survey attendants. Also, there is a similar view from influence of two remaining groups when they both affect to $62.5 \%$ (from close friends) and $61.3 \%$ (from other important people).

Consumers, perceiving strong behavioral control, shows their high independence when reaching the decision. Results display quite positive overview of customers in this factor through $62.2 \%$ of customers claim that buying green household appliances is totally under their control. A lower figure for consumers performing behavior in case of receiving advice from friends $-57.4 \%$. Whereas, just nearly a half of survey participants have enough resources to purchase green household appliances.

In terms of trend, 3 out of 5 people, attending in the questionnaire, buy green products if people around them all choose the same. There is $58.5 \%$ of consumers believe in decision of buying green household appliances of majority while the figure for customers understanding of the products created from their family members, colleagues and friends is $56.6 \%$. On the contrary, about $67 \%$ of consumers' family members or friends do not use household appliances which are positive for environment. 


\section{Data Analysis and Research Results}

\subsection{Reliability and validity of the scales}

Authors used Cronbach's Alpha and Exploratory Factor Analysis (EFA) to evaluate reliability and validity of the scales. All the variables have Cronbach's Alpha from 0.668 to 0.885 and all of 19 observed variables are included because of having Corrected Item - Total Correlation higher than 0.3.

Table 2. Reliability analysis results

\begin{tabular}{|c|c|c|c|c|}
\hline \multirow{2}{*}{ Factor } & \multicolumn{2}{|l|}{ Number of observed variables } & \multirow{2}{*}{ Cronbach's Alpha } & Factor loading minimum \\
\cline { 2 - 5 } & Before & After & & \\
\hline Attitude & 3 & 3 & $\mathbf{0 . 8 8 5}$ & 0.753 \\
\hline Subjective norm & 3 & 3 & $\mathbf{0 . 8 0 4}$ & 0.586 \\
\hline Perceived behavioral control & 3 & 3 & $\mathbf{0 . 6 7 1}$ & 0.425 \\
\hline Trend & 4 & 4 & $\mathbf{0 . 6 6 8}$ & 0.352 \\
\hline Consumption intention & 3 & 3 & $\mathbf{0 . 7 8 7}$ & 0.598 \\
\hline Consumption behavior & 3 & 3 & $\mathbf{0 . 8 3 6}$ & 0.645 \\
\hline
\end{tabular}

Exploratory factor analysis (EFA) was carried out by using the method Principle components analysis and Varimax rotation to assess the validity of the scales. In this test, variables with the extraction less than 0.5 continue disqualified. The first EFA analysis result eliminated X041 because loading factor is less than 0.5. Continuing to analyze EFA the second time, the result of factor was satisfactory in all the criteria. KMO and Bartlett's test (KMO at 0.818 in accepted range $0.5<\mathrm{KMO}<1$ and Bartlett's results have Sig. $=0.000<0.05$ ) showed that the observed variables are correlated with each other on overall. The number of factors extracted are 4 factors, rotation Cumulative Sum of Squared Loading Value showed that 4 factors explained $69.9 \%$ of data variation. At this point, the authors have identified 4 key groups of factors that will be instead of the 4 potential variables as the original hypothetical model. Based on analysis results, the two scales of intention and consumer behavior fall into one group, thereupon, authors decided to check again the answer of survey participants and compare with the results of consumer interviews. Authors found that from the intent of green consumption to the behavior of green consumption in the field of electronic appliances there are almost no gap. Therefore, authors decided eliminated consumption intention scale and changed the symbol of the consumption behavior scale from (Y02) to (Y) in particular has show below:

Independent Factors: (X1) Attitude, (X2) Subjective Norm, (X3) Perceived Behavior Control, (X4) Trend

Dependent Factor: (Y) Consumption Behavior 
Table 3. Independent variable - exploratory factor analysis (EFA) result

\begin{tabular}{|c|l|c|c|c|c|}
\hline Code & \multicolumn{1}{|c|}{ Variables } & \multicolumn{3}{c|}{$\begin{array}{c}\text { Rotated Component } \\
\text { Matrix }\end{array}$} \\
\hline & & \multicolumn{3}{|c|}{ Component } \\
\hline X1 & Attitude & 1 & 2 & 3 & 4 \\
\hline X011 & I like to buy green household appliance & 0.849 & & & \\
\hline X012 & Buying green household appliance is a good idea & 0.853 & & & \\
\hline X013 & I am interested in buying green household appliance & 0.821 & & & \\
\hline X2 & Subjective Norm & & & & \\
\hline X021 & My family advise me to buy green household appliance & & 0.681 & & \\
\hline X022 & My friends advise me to buy green household appliance & & 0.858 & & \\
\hline X023 & $\begin{array}{l}\text { Important others advise me to buy green household } \\
\text { appliance }\end{array}$ & & 0.856 & & \\
\hline X3 & Perceived Behavior Control & & & & \\
\hline X031 & $\begin{array}{l}\text { I will buy green household appliances even my friends tell } \\
\text { me not to buy }\end{array}$ & & & 0.553 & \\
\hline X032 & Buying green household appliances is within my control & & & 0.809 & \\
\hline X033 & I can afford to buy green household appliance & & & 0.779 & \\
\hline X4 & Trend & & & & \\
\hline X042 & Most of my close friends and family use green household & & & & \\
\hline X043 & I will buy if people surrounding me choose green household & & & & 0.830 \\
\hline X044 & I believe in the choice of the majority & & & \\
\hline
\end{tabular}

\subsection{Hypothesis testing}

The results of Pearson's correlation analysis show that there exists are linear correlation between the dependent variable $\mathrm{Y}$ and the independent variables $\mathrm{X} 1, \mathrm{X} 2, \mathrm{X} 3, \mathrm{X} 4$.

Results of linear regression analysis the effect between the factors affecting green consumption behavior in Table 3 with a 5\% significance indicate the relationship of 4 independent variables (X1) Attitude (Sig.=0.000), (X2) Subjective norm (Sig.=0.001), (X3) Perceived behavioral control $(\mathrm{Sig} .=0.000),(\mathrm{X} 4)$ Trend $(\mathrm{Sig} .=0.000)$ to dependent variables (Y) Consumption behavior, the coefficient $R^{2}$ adjusted to 0.409 means that the linear regression model was built in accordance with the data set at $40.9 \%$. Next, the analysis results show that the Sig value of the F-test is very small $\left(=0.000^{b}\right)$ and VIF coefficient of the independent variables is less than 2 , so, no collinearity phenomenon occurs. 
Table 4. The regression results

Coefficients $^{\mathbf{a}}$

\begin{tabular}{|c|c|c|c|c|c|c|c|c|}
\hline \multirow{2}{*}{\multicolumn{2}{|c|}{ Model }} & \multicolumn{2}{|c|}{$\begin{array}{c}\text { Unstandardized } \\
\text { Coefficients }\end{array}$} & \multirow{2}{*}{$\begin{array}{c}\begin{array}{c}\text { Standardized } \\
\text { Coefficients }\end{array} \\
\text { Beta } \\
\end{array}$} & \multirow[t]{2}{*}{$\mathrm{t}$} & \multirow[t]{2}{*}{ Sig. } & \multicolumn{2}{|c|}{ Collinearity Statistics } \\
\hline & & B & Std. Error & & & & Tolerance & VIF \\
\hline \multirow{5}{*}{1} & (Constant) & .935 & .194 & & 4.819 & .000 & & \\
\hline & $\mathrm{X} 1$ & .277 & .042 & .329 & 6.538 & .000 & .654 & 1.530 \\
\hline & $\mathrm{X} 2$ & .141 & .044 & .154 & 3.232 & .001 & .735 & 1.360 \\
\hline & $\mathrm{X} 3$ & .156 & .042 & .178 & 3.694 & .000 & .718 & 1.392 \\
\hline & $\mathrm{X} 4$ & .209 & .041 & .221 & 5.072 & .000 & .878 & 1.138 \\
\hline
\end{tabular}

a. Dependent Variable: Y

Figure 2. Model of research on factors affecting green consumption behavior of household appliances in Vietnam

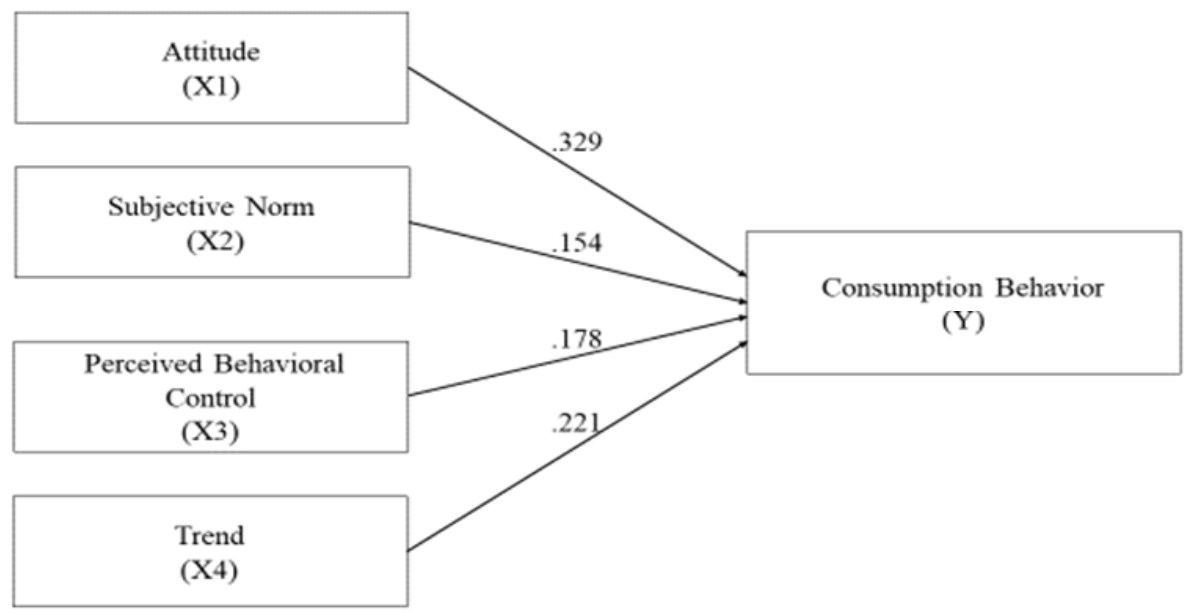

The regression results assessing the impact of 4 factors on (Y) Consumption behavior as follows:

$Y=0.329(X 1)+0.154(X 2)+0.178(X 3)+0.221(X 4)$

This indicates that, with the significance of 5\% there are 6 factors impacts on green consumption behavior, the impact level of 6 factors in descending order are:

(1)X1 Attitude $(\beta=0.329),(2) \mathrm{X} 4$ Trend $(\beta=0.221),(3) \mathrm{X} 3$ Perceived Behavior Control $(\beta=0.178)$, (4) Subjective norm $(\beta=0.154)$, the standardized coefficients $\beta$ eta $>0$ show a positive relationship between the independent variables and green consumption behavior. In which, factor (X1) Attitude is assessed as having the strongest impact on green consumption behavior and the weakest factor impact on green consumption behavior is (X4) Subjective norm

\section{Conclusion, Recommendations, Limitations and Further Research Directions}

\subsection{Conclusion}

The research shows that 4 factors are affecting green consumption behavior for household appliances in Vietnam. Of which two variables named "Attitude" and "Trend" are respectively the two strongest factors, followed by Perceived behavioral control and Subjective norm. It can be seen that the customer's mindset about green 
consumption behavior is quite elevated; thus, they are keen on using energy-saving household electronic products. Those clients would believe in the choices of common views from their friends, families and social trends since they are living in a close community and each decision is strongly influenced by other relationships along with their positive attitude towards environmental protection and saving energy has positive influence on green behavior.

\subsection{Recommendations}

\section{- For government agency}

Changing citizen's awareness about green consumption especially through mass media channels such as television, radio and social networks to improve people's understanding of this issue.

Organizing practical polices to boost ecological consumption such as create "Collecting expired things and renewing" campaign that takes place on weekends for people to collect used products and bring them to preestablished places to recycle and exchange products green environmental protection.

Promoting product-manufacturing enterprises, expand the scope of trade or subsidize for energy-efficient household goods in places where there is a shortage of distribution agents.

\section{- For manufacturing businesses}

Each facility needs to update new trends and technologies in the green product manufacturing and especially diversify distribution channels so that customers are eager to use environmental - protection goods timely.

Putting the words "credibility and quality" as a precondition in every business.

- For distributors, retail businesses

Incorporating closely with manufacturers in bringing green products to consumers in a convenient and speedy way.

The distributors, electronic centers should elaborate and arrange clearer the location of the Energy-saving household electronic products in both traditional stalls and tailor stands to advertise this product so that consumers can follow easily especially potential shoppers.

Marketing and propagandizing about energy-saving household electronic products. Consequently, users can realize the benefits of using green products; for instance, saving energy or and reducing the monthly electricity bill.

\section{- $\quad$ For consumers}

Updating official announcements from the government's media channels to prevent misleading in green consumption.

Having consciousness in protecting the environment from uncomplicated but effective tasks such as saving electricity and water, limiting the use of plastic bags, or even reading full information before starting to make use of green products.

Encouraging colleagues and relatives to use eco-friendly stuff, thereby creating a trend of green consumption in Vietnam, such as prioritizing the use of clean-fuel energy and recycling materials for the environment.

\subsection{Limitations and further research directions}

The scope of this study is only in the major city in Vietnam: Hanoi; therefore, these conclusions can be partial. The nation's capital is at the forefront of using renewable energy sources and energy-efficient appliances. People in this area have a higher living standard, knowledge, income, etc.

Due to Vietnam's geography complication, for the future study, researchers need to increase the size of the survey, such as other groups of the residents. Moreover, cultural factors; other regions with different climatic conditions: delta area, the mountainous area can be influenced.

\section{References}

Ajzen, I. (1991), "The Theory of Planned Behavior, Organizational Behavior and Human Decision Processes". 50(2), 179-211. http://doi.org/10.1016/0749-5978(91)90020-T

Al-Azzam A. F. M. Evaluating the antecedents of online consumer purchasing behavior: an empirical study based on the Theory of Planned Behavior. International Journal of Economics, Commerce and Management 2014:11(4):1-18. 
Chih-Cheng Chen, Chien-Wen Chen \& Yi-Chun Tung (2018), "Exploring the Consumer Behavior of Intention to Purchase Green Products in Belt and Road Countries: An Empirical Analysis". Available at: https://www.researchgate.net/publication/323889437_Exploring the Consumer_Behavior_of_Intention to_Purc hase_Green_Products_in_Belt_and_Road_Countries_An_Empirical_Analysis.

Hoang Trong Hung, Huynh Thi Thu Uyen, Huynh Thi Nhi (2018), Factors affecting consumers' green purchase behavior in Hue city, Hue University Journal of Science: Economics and Development, 127 (5A), 199-212.

Hung V.Nguyen, Cuong Hung Nguyen, Thoa Thi Bao Hoang (2018), "Green consumption: Closing the intentionbehavior gap" https://www.researchgate.net/publication/326868782_Green_consumption_Closing the intentionbehavior_gap.

JungHwa Son (2007), Indian consumer purchase behavior of foreign brand jeans https://shareok.org/bitstream/handle/11244/8607/Son_okstate_0664M_2591.pdf?sequence=1.

Kim Y. G, Jang S. Y., Kim A. K. Application of the theory of planned behavior to genetically modified foods: Moderating effects of food technology neophobia. Food Research International 2014:62:9 47-954. doi:10.1016/j.foodres.2014.03.057.

Maichum K., Parichatnon S., Peng K.-C. Application of the Extended Theory of Planned Behavior Model to Investigate Purchase Intention of Green Products among Thai Consumers. Sustainability 2016:8(10):120. doi:10.3390/su8101077.

Nam, Changhyun \& Dong, Huanjiao \& Lee, Young-A. (2017). Factors influencing consumers' purchase intention of green sportswear. Fashion and Textiles. 4. 10.1186/s40691-017-0091-3.

Nchise A. An Empirical Analysis of the Theory of Planned Behavior: A Review of Its Application on E-democracy Adoption Using the Partial Least Squares Algorithm. JeDEM 2012:4(2):171-182. doi:10.29379/jedem.v4i2.129.

Russo D. A., Stochl J., Painter M., Shelley G. F., Jones P. B., Perez, J. Use of the Theory of Planned Behaviour to assess factors influencing the identification of students at clinical high-risk for psychosis in 16+ Education. BMC Health Services Research 2015:15:411. doi:10.1186/s12913-015-1074-y.

Shwu-Ing Wu \& Jia-Yi Chen, 2014, A model of green consumption behavior constructed by the theory of planned behavior, Researchgate

https://www.researchgate.net/publication/287504382 A Model of Green Consumption Behavior Constructed by the Theory of Planned Behavior.

Steven Webb (1993), Women's Incomes: Past, Present and Prospects, https://doi.org/10.1111/j.14755890.1993.tb00436.x.

Syed S. Alam, Chieh-Yu Lin, Maisarah Ahmad, Nor A. Omar \& Mohd H. Ali (2019), "Factors Affecting EnergyEfficient Household Products Buying Intention: Empirical Study" https://www.researchgate.net/publication/334590120_Factors_Affecting_Energy Efficient_Household_Products_Buying_Intention_Empirical_Study.

Urban J., Zverinova I., Scasny M. What Motivates Czech Consumers to Buy Organic Food? Czech Sociological Review 2012:48(3):509-536. 